\title{
Aptamer-Functionalized Dendrimer Delivery IncRNA MEG3 Enhances Castration-Resistant Prostate Cancer Gene Therapy
}

\section{Zongguang Tai}

Shanghai Skin Disease Hospital https://orcid.org/0000-0001-5603-745X

Jinyuan Ma

Shanghai Skin Disease Hospital

Jianing Ding

Shanghai Skin Disease Hospital

Huijun Pan

Shanghai Skin Disease Hospital

\section{Rongrong Chai}

Shanghai Skin Disease Hospital

Congcong Zhu

Shanghai Skin Disease Hospital

\section{Zhen Cui}

Shanghai Skin Disease Hospital

\section{Zhongjian Chen}

Shanghai Skin Disease Hospital

Quangang Zhu ( $\sim$ qgzhu@126.com )

Shanghai Skin Disease Hospital

\section{Research}

Keywords: IncRNA MEG3, castration-resistant prostate cancer, aptamer, PAMAM, gene therapy

Posted Date: August 31st, 2020

DOl: https://doi.org/10.21203/rs.3.rs-67717/v1

License: (c) (i) This work is licensed under a Creative Commons Attribution 4.0 International License.

Read Full License 


\section{Abstract}

Androgen castration therapy is an effective treatment method for prostate cancer patients who cannot be completely cured by surgery. However, drug resistance often leads to treatment failure and poor prognosis. For castration-resistant prostate cancer (CRPC), some new treatment methods have been gradually put into clinical validation or use. Considering the side effects of traditional treatment, gene therapy has been applied in recent studies to combat prostate cancer (PCa). A 19-nt RNA aptamer, termed as EpDT3, is endocytosed when bound to epithelial cell adhesion molecule EpCAM-overexpressing cells, including various types of prostate cancer cells. Therefore, poly (amidoamine) dendrimer (PAMAM) conjugated with EPDT3 on the surface was developed for gene delivery targeting the CRPC. Moreover, the PAMAM-PEG-EpDT3 vehicles were accumulated in CRPC cells. The CRPC-inhibitory effect of PAMAM modified with EpDT3 was significantly higher than that of the unmodified construct when loading the plasmid that encodes long noncoding (Inc) RNA MEG3 (pMEG3). In summary, the above results suggested that PAMAM-PEG-EpDT3/pMEG3 nanoparticles (NPs) have great potential for enhancing CRPC gene therapy.

\section{Background}

Prostate cancer ( $\mathrm{PCa})$ is the most common malignant tumor on the prostatic epithelium in the male genitourinary system, which greatly reduces the survival time and the life quality of PCa patients. Surgical excision, radiation therapy, hormonal therapy, and chemotherapy are the primary methods for the treatment of PCa [1, 2]. However, limitations such as severe complications, iatrogenic injury, drug toxicity, and resistance persist when applying the above treatment $[3,4]$. Specifically, castration-resistant prostate cancer (CRPC) is the fatal stage of prostate cancer [5]. How to prolong the time to CRPC is yet under investigation with respect to the treatment of hormone-sensitive metastatic prostate cancer. Recently, gene therapy has been used for delivering specific nucleotide sequences into target cells, where they can correct or compensate for the existing gene defect or abnormality that leads to specific diseases, interfere with the expression of some proteins, or correct gene mutations $[6,7]$. Thus, gene therapy could improve targeting ability and have fewer side effects for the treatment of PCa.

EpCAM (also known as TACSD1 or CD326) is a glycoprotein highly expressed on the surface of the majority of malignant epithelial tumor cells. As one of the most strongly expressed tumor surface antigens at present, it promotes cell proliferation, differentiation, and migration and accelerates cell cycle, immune escape, and other biological functions $[8,9]$. Other studies have found that EpCAM is associated with radiation-chemotherapy resistance and metastasis of $\mathrm{PCa}$ by activating the $\mathrm{PI} / \mathrm{Akt} / \mathrm{mTOR}$ signaling pathway [10]. EpCAM was highly expressed in PCa cells with in-situ and lymph node metastasis, especially in CRPC and $>80 \%$ of circulating PCa cells $[11,12]$, which makes it a promising target for antibodies or other alternative binding molecules on PCa cells.

Aptamers are single-stranded RNA or DNA molecules that form hairpin and additional three-dimensional (3D) structures determined by specific sequences to achieve target recognition $[13,14]$. Furthermore, a 
host of aptamers selected and generated from large synthetic libraries through the systemic evolution of ligands by exponential enrichment (SELEX) are optimal candidates for drug delivery by binding to specific targets [15]. Shigdar et al. developed a 19-nt RNA aptamer that interacted specifically with cancer cells that overexpress EpCAM on the cell surface and could be endocytosed after binding to the molecule [16, 17]. The aptamer, named EpDT3, can further target EpCAM-overexpressing PCa cells by modifying specific drug or gene carriers, thereby effectively and accurately fighting against PCa.

Noncoding RNA (ncRNA) is a general term for the functional RNAs that cannot encode and translate proteins, including long noncoding RNAs (IncRNA) and short ncRNAs (such as siRNA and miRNA). Noncoding RNA plays a major role in chromosome transcription and inactivation, gene expression and shutdown, cell cycle, and apoptosis [18]. Currently, in gene therapy studies, the use of short noncoding RNAs, such as siRNA and miRNA, are preferred for the treatment of various cancers [19]. In recent years, IncRNA has been found to be closely related to the occurrence and development of tumors [20]. Among these, IncRNA MEG3 is expressed in most normal tissues, but can hardly be detected in human tumor cells. It is speculated that MEG3 inhibits tumor growth through ectopic expression [21]. Further studies on MEG3 showed that it inhibited the synthesis of DNA in meningioma cells by stimulating p53-mediated transcription, thereby inhibiting the proliferation of cancer cells $[22,23]$. Luo et al. also confirmed that IncRNA MEG3 inhibited the proliferation and induced apoptosis of of CRPC cells by affecting the expression of p53 [24]. In conclusion, IncRNA MEG3 is a promising tumor suppressor gene for clinical application of CRPC.

However, several studies have reported the mechanism of IncRNA with few application in the treatment of cancer [25]. Unfortunately, only a few IncRNAs exert tumor suppressor function, and due to the excessive length, they are difficult to synthesis and presented poor stability $[20,26,27]$. Therefore, we constructed plasmid-encoding IncRNA MEG3 (pMEG3) to overcome the stability defect of IncRNA. In addition, there is no suitable and effective vector to deliver these IncRNAs into target cells. How to deliver IncRNA into tumor cells, such as PCa, in vivo, through targeted the nano-drug delivery system has become the focus of translational medicine research.

Polyamine (PAMAM) dendrimers are the earliest and most widely distributed dendrimers with layered 3D structures that are extensively used in medical applications. Similarly, the surface groups on PAMAM can be used as anchor points which can bind or absorb different types of reagents to achieve a variety of functions, such as improving target capability, modifying solution behavior, and reducing toxicity [28, 29]. Herein, EpDT3 and polyethylene glycol (PEG) were attached on the surface of PAMAM to develop a new vector PAMAM-PEG-EpDT3 for pMEG3 delivery in CRPC cells. CRPC cell lines and its xenograft on nude mice were selected as CRPC model to evaluate the targeting ability and cellular uptake mechanism of PAMAM-PEG-EpDT3, as well as the therapeutic effect of PAMAM-PEG-EpDT3/pMEG3 nanoparticles (NPs) loaded with pMEG3 (Fig. 1).

\section{Results And Discussion}




\section{Preparation and characterization of PAMAM-PEG-EpDT3/pMEG3 NPs}

The purity of commercially synthesized EpDT3 was determined by high-pressure liquid chromatography (HPLC), and the data showed $>90 \%$ purity. Mass spectrometry (MS) determined the molecular weight of EpDT3 as 6285.6 and 5'Cy3-EpDT3 as 6853.8 (Figure 2A and 2B).

The synthesis of PAMAM-PEG and PAMAM-PEG-EpDT3 is illustrated in Figure 2C. The characteristic group of PAMAM-PEG-EpDT3 was verified by ${ }^{1} \mathrm{H}$-NMR spectra. As shown in Figure 2D, PAMAM skeleton peak appeared at 2.2-3.4 ppm. In addition, the methylene characteristic absorption peak ( $\delta 3.6$ ) was verified in the ${ }^{1} \mathrm{H}-\mathrm{NMR}$ spectra of PAMAM-PEG and PAMAM-PEG-EpDT3, indicating that PEG was conjugated with PAMAM. The amino group on the surface of PAMAM reacted with the succinimide of MAL-PEG-NHS, while the disappearance of the characteristic peak of MAL in the ${ }^{1} \mathrm{H}$ NMR spectrum of PAMAM-PEG-EpDT3 further suggested that EDDT3 was linked to PEG. The introduction of PEG not only partially blocks the positive electricity of PAMAM and reduces toxicity but also makes PAMAM-PEG as the gene carrier with prolonged circulatory effect [30]. Consequently, PAMAM-PEG-EpDT3 was formed due to the reaction between the sulfhydryl of EpDT3 and MAL on one end of the PEG chain (Figure $2 \mathrm{C}$ ). Since MAL and SH react under mild conditions, PAMAM-PEG-EpDT3 was synthesized while EpDT3 activity was maintained.

Newly prepared PAMAM, PAMAM-PEG, and PAMAM-PEG-EpDT3 were incubated with varying amounts of pMEG3 to achieve the pMEG3-loaded NPs. Agarose gel electrophoresis was used to evaluate the binding ability of pDNA. As shown in Figure 3A, the vehicles encapsulate pMEG3 without any leakage when the N/P ratio is $>10$. Next, we selected PAMAM-PEG-EpDT3/pMEG3 NPs prepared at N/P ratio 15 for further evaluation. Figure 3B shows that the mean particle size of PAMAM-PEG-EPDT3/pMEG3 NPs was $180 \pm 0.15 \mathrm{~nm}$ with a polydispersity of 0.236 and zeta potential $19.7 \pm 0.23 \mathrm{mV}$ (Figure $3 \mathrm{C}$ ). The appropriate particle size and zeta potential ensure that the NPs are enriched in tumor tissues through the enhanced permeability and retention effect (EPR) effect and taken up by tumor cells [31, 32].

\section{Evaluation of the targeting ability of EpDT3 and PAMAM-PEG-EpDT3}

PC-3 and DU-145 cells expressing EpCAM were analyzed as CRPC cell models in vitro. Shigdar et al. suggested that the aptamer EpDT3 binds specifically to EpCAM expressed on the surface of CRPC cells $[11,12]$ and mediates endocytosis. The localization of EpDT3 was investigated by CLSM. As shown in Figure 4A, the signals of Cy3-EpDT3 in PC-3 and DU-145 cells were distributed in both cytoplasm and cell membranes, suggesting that EPDT3 is successfully initialized by CRPC cells.

The selective and effective uptake of nanomaterials by target cells is crucial to the ultimate therapeutic effect [33, 34]. Therefore, EpDT3 increases the uptake of nanomaterials in CRPC cells. To further clarify the uptake mechanism, we first loaded the commercially available fluorescent probe BODIPY onto PAMAM-PEG-EpDT3, and then incubated PC-3 and DU-145 cells with different concentrations of BODIPYPAMAM-PEG-EpDT3. Subsequently, the concentration-dependent cellular uptake of PAMAM-PEG-EpDT3 was evaluated in PC-3 and DU-145 cells qualitatively (Figure 4B). It was observed that the BODIPY signal 
increases in a concentration-dependent manner, indicating that EpDT3 increases the cellular uptake of PAMAM. When the concentration of BODIPY-PAMAM-PEG-EpDT3 was $0.05-1 \mu \mathrm{M}$, the uptake in PC-3 and DU-145 cells was positively correlated with the concentration of the vehicle.

Quantitative analysis by flow cytometry also revealed that compared to BODIPY-PAMAM, the cellular uptake of BODIPY-PAMAM-PEG-EpDT3 is increased. The increase in BODIPY-PAMAM-PEG-EpDT3 concentration led to an increase in the positive rate of BODIPY fluorescence in PC-3 cells from $77.97 \%$ to 92.14\% while in DU-145 cells from $64.68 \%$ to $97.22 \%$. The cellular uptake of PAMAM-PEG-EpDT3 was higher than that of PAMAM-PEG, which might be attributed to the ability of EpDT3 to combined with CRPC cells (Figure 4C). This phenomenon was consistent with the results observed by CLSM.

\section{Endocytosis mechanism study}

The mechanism of the endocytosis of BODIPY-PAMAM-PEG-EPDT3 in PC-3 cells was examined. As shown in Figure 5A, we observed that the green fluorescence intensity in each group declined after the treatment of endocytosis inhibitors. Compared to the control group, the fluorescence intensity was significantly decreased in filipin and phenylarsine oxide-treated groups, while colchicine had a lower influence on cellular uptake. When BODIPY-PAMAM-PEG-EpDT3 was incubated with cells at $4{ }^{\circ} \mathrm{C}$, the cellular uptake of the vehicles was reduced significantly, indicating that the endocytosis of BODIPYPAMAM-PEG-EpDT3 was an energy-dependent pathway.

The mechanism of the cellular uptake of PAMAM-PEG-EpDT3/pMEG3 by PC-3 cells is shown in Figure 5B. Interestingly, the decrease in the red fluorescence intensity of EMA was observed in all the endocytosis inhibitor-treated groups. Similarly, the conditions presented in the study of endocytosis mechanism of BODIPY-PAMAM-PEG-EpDT3-, filipin-, and phenylarsine oxide-treated groups showed lower red fluorescence as compared to the control group, while the decrease in the colchicine group was not significant. Thus, it can be deduced that this process was energy-dependent. In addition, the endocytosis mediated by EpCAM and EpDT3 and the electrostatic interaction between the cationic surface of PAMAMPEG-EpDT3 and cell membrane might also mediate endocytosis. After the treatment with excessive EpDT3, the cellular uptake of PAMAM-PEG-EpDT3/EMA-DNA declined markedly, suggesting that EpDT3 specifically binds to the cell membrane and enhances the cellular uptake of PAMAM-PEG-EpDT3/pMEG3.

\section{In vitro anticancer efficacy}

PAMAM and PAMAM-PEG-EpDT3 empty vectors were incubated with PC-3 and DU-145 cells, and their effects and potential toxicity were studied by CCK-8 analysis. Notably, at the same concentration, the cell viability of the PAMAM group was significantly lower than that of the PAMAM-PEG-EpDT3 group. This indicated that the modification of PEG and EPDT3 markedly reduces the toxicity of PAMAM, thereby improving the biocompatibility of the NPs (Figure 6A and 6B).

According to the previous reports [24], the expression of IncRNA MEG3 in PCa tissues was significantly downregulated as compared to that of the adjacent normal prostate tissues. LncRNA MEG3 inhibits 
tumor cell proliferation or induces tumor cell apoptosis by stimulating p53-dependent transcription. Therefore, we constructed pMEG3-expressing IncRNA MEG3 and constructed PAMAM-PEGEpDT3/pMEG3 NPs to study its gene therapy effect on CRPC cells.

Next, the antitumor effect in vitro was evaluated using the CCK-8 assay. After incubation with CRPC cells for $48 \mathrm{~h}$, dose-dependent cytotoxicity was observed in the PAMAM-PEG-EpDT3/pMEG3 and PAMAMPEG/pMEG3 complexes as compared to the control group (Figure 6C and 6D). This indicates that PAMAM-PEG-EpDT3/pMEG3 and PAMAM-PEG/pMEG3 have an inhibitory effect on androgen nonreactive PC-3 and DU-145 cells. In PC-3 cells, the half-maximal inhibitory concentration (IC50) of PAMAMPEG-EpDT3/pMEG3 and PAMAM-PEG/pMEG3 was 2.877 and $6.06 \mu \mathrm{M}$, respectively. Therefore, compared to PAMAM-PEG/pMEG3, PAMAM-PEG-EpDT3/pMEG3 has a stronger inhibitory effect on CRPC cells, which could be mainly due to the increased aptamer-mediated cell uptake.

\section{In vivo anticancer efficacy and safety evaluation}

Nude mice were injected with PC-3 cells subcutaneously to establish a CRPC model. Then, the anti-CRPC efficacy of PAMAM-PEG-EpDT3/pMEG3 NPs was tested in tumor-bearing nude mice. The tumor images of CRPC tumor-bearing nude mice are shown in Figure 7A. The Saline group and the PAMAM-PEGEpDT3/pDNA group had relatively large tumor volumes, followed by the PAMAM-PEG/pMEG3 group. Among the four groups, PAMAM-PEG-EpDT3/pMEG3 group exhibited the smallest tumor volume. Intriguingly, the tumor volume data showed that PAMAM-PEG/pMEG3 and PAMAM-PEG-EpDT3/pMEG3 effectively inhibits the growth of PC-3 transplanted tumors. Moreover, PAMAM-PEG-EpDT3/pMEG3 exerted a better anticancer effect than PAMAM-PEG/pMEG3, which could be attributed to the strong tumor targeting of PAMAM-PEG/pMEG3, facilitating an easy entry of the NPs into tumor cells, which is beneficial in gene therapy.

Figure 7B shows the weight of the tumor isolated after the experiment. Compared with the saline group, the tumor inhibition rate of the PAMAM-PEG-EpDT3/pDNA group was only $5.35 \%$, and no obvious antitumor effect was shown. The tumor inhibition rates were $40.95 \%$ and $63.34 \%$, respectively. The latter had a significantly smaller tumor weight and a higher tumor suppression rate, which had a stronger effect on inhibiting the growth of CRPC cell transplanted tumors. The above results indicate that the main reason why PAMAM-PEG/pMEG3 and PAMAM-PEG-EpDT3/pMEG3 inhibit tumor growth is the expression of LncRNA MEG3, not the role of the nanocarrier itself. In addition, the modification of EpDT3 aptamer can make more NPs accumulate in the CRPC site, improve the efficiency of pMEG3 expressing LncRNA MEG3 in tumors, and thus play a better antitumor effect.

Figure 7C shows the average weight change of nude mice with transplanted tumor in each group. The weight of the nude mice in each group was relatively stable during the first 13 days, and the weight increased slightly, with an average weight distribution of $22-25 \mathrm{~g}$. In the later period of the experiment, the weight of the nude mice in each group began to decline. Among them, the body weight of nude mice in the saline group and PAMAM-PEG-EpDT3/pCDNA group decreased significantly, down to about $19 \mathrm{~g}$. The weight of nude mice in the PAMAM-PEG/pCDNA MEG3 group and PAMAM-PEG-EpDT3/pCDNA MEG3 
group decreased slowly and remained above $20 \mathrm{~g}$. This is because with the proliferation of tumor blood vessels, the tumor tissue began to absorb nutrients from the nude mouse body, so the weight of nude mice showed a downward trend in the later period. However, in the PAMAM-PEG/pMEG3 group and PAMAM-PEG-EPDT3/pMEG3 group, the tumor growth rate was slower and the tumor volume was relatively small due to the drug treatment, so the weight loss of nude mice was not obvious. At the same time, the results of changes in body weight also indicate that the nanocarrier itself has little side effects.

To assess the safety of the treatment system, we injected the NPs intravenously in healthy mice and collected blood samples 24 hours later. Aspartate transferase (AST) and glutamic acid alanine transferase (ALT) are two important indicators of liver function, and creatinine (CRE) is an important indicator of kidney function. Figure 7D shows the ALT, AST and CRE test results of different mouse groups. There is no significant difference between the data of each group, indicating that neither nanocarriers nor gene-carrying NPs will damage the liver and kidney functions of nude mice and are safe gene delivery systems.

\section{Histological analysis}

Figure 8 shows the hematoxylin and eosin (H\&E) staining results of tumor tissues of different drug delivery groups. The saline and PAMAM-PEG-EpDT3/pDNA groups showed good tumor growth, no areas of necrosis, large tumor cell nuclei, and relatively clear edges, indicating that the nanocarriers had no obvious toxicity and side effects. The PAMAM-PEG/pMEG3 group and the PAMAM-PEG-EpDT3/pMEG3 group had loose or vacuolar tumor tissue, and deep nuclear staining (as shown by the black arrow) was also observed in PAMAM-PEG-EpDT3/pMEG3 or Fragmentation and dissolution (as indicated by the red arrow), accompanied by infiltration of many neutrophils. These results indicate that LncRNA MEG3 has obvious CRPC inhibition, while EpDT3 aptamer-modified NPs have a stronger anti-CRPC effect.

After a series of studies on the efficacy of PAMAM-PEG-EpDT3/pMEG3 NPs against CRPC, we further investigated the mechanism of PAMAM-PEG-EpDT3/pMEG3 NPs against CRPC by immunohistochemistry. The expressions of Ki67, Bcl-2, Cyclin D1, and p53 proteins in tumor tissues of different drug delivery groups were analyzed.

Ki67 is a nuclear antigen associated with proliferating cells. Its function is closely related to mitosis and is indispensable in cell proliferation. Ki67 can be used to label cells outside the G0 phase of the cell cycle, which is termed as the proliferation index of cells [35-37]. The higher the positive expression of Ki67, the higher the proportion of cells in the proliferation cycle and the faster the rate of tumor growth. The Hscore of Ki67 protein in the PAMAM-PEG-EpDT3/pDNA, PAMAM-PEG/pMEG3, and PAMAM-PEGEpDT3/pMEG3 groups was 54.77, 34.71, and 12.64, respectively. Furthermore, PAMAM-PEGEpDT3/pDNA group showed an intense staining, the highest $\mathrm{H}$-score, and the maximal expression of Ki67 (Figure 8). Compared to the other groups, PAMAM-PEG-EpDT3/pDNA group showed superficial staining, low H-score, and low expression of Ki67, indicating that IncRNA MEG3 significantly inhibits the proliferation of CRPC cells. Additionally, EpDT3 aptamer enabled the drugs to accumulate in tumor sites, which improved the transfection efficiency of pMEG3 and inhibited the proliferation of cancer cells. 
The expression of Bcl-2 protein is an indicator of apoptosis [38-40]. As shown in Figure 8, both the Saline and the PAMAM-PEG-EpDT3/pDNA groups showed an intense staining and high positive expression of Bcl-2, while the PAMAM-PEG/pMEG3 and PAMAM-PEG-EpDT3/pMEG3 groups both showed a reduced staining intensity and low positive expression of Bcl-2, indicating that LncRNA MEG3 significantly promotes the apoptosis of CRPC cells.

Immunohistochemical analysis of Cyclin D1 protein in tumor tissues of different groups are shown in Figure 8. Cyclin D1 protein is expressed in all the drug delivery groups. The Saline group and PAMAMPEG-EpDT3/pDNA group exhibited a high Cyclin D1 expression, while the PAMAM-PEG-/pMEG3 and PAMAM-PEG-EpDT3/pMEG3 groups showed reduced staining intensity and $\mathrm{H}$-score, indicating a downregulated expression. Cyclin D1 is a key protein regulating the G1 phase of the cell cycle, and its main function is to promote cell proliferation. Also, it is a proto-oncogene, and its overexpression leads to uncontrolled cell proliferation and malignancy of tumors [41-43]. These results indicated that IncRNA MEG3blocks cell cycle and inhibits the proliferation of CRPC cells.

Finally, we detected the expression of p53 protein in all groups. The wild-type P53 gene is a tumor suppressor that inhibits the proliferation and differentiation of cancer cells and regulates the $\mathrm{G} 1$ phase of the cell cycle [44]. When mutated or inactivated, p53 becomes an oncogene, causing malignant proliferation of tumor cells, which is closely related to the occurrence and evolution of tumors [45]. The wild-type p53 protein is unstable and has a short half-life, rendering it difficult to be detected by immunohistochemistry, and mutations in the TP53 have previously been confirmed a strong correlation with upregulated p53 expression as measured by IHC [46-48].

As shown in Figure 8, the Saline group had the highest level of p53, followed by the PAMAM-PEGEpDT3/pDNA, PAMAM-PEG/pMEG3, and PAMAM-PEG-EpDT3/pMEG3 groups. The level of p53 was reduced, indicating that IncRNA MEG3 significantly inhibits the proliferation of CRPC cells. Compared to the PAMAM-PEG/pMEG3 group, PAMAM-PEG-EpDT3/pMEG3 group showed relatively shallow staining and low H-Score. The low positive expression of mutated p53 indicated that Inc MEG3 was transferred to CRPC cells through the targeting role of EpDT3 aptamer, thereby inhibiting cell proliferation.

\section{Conclusion}

In this study, PAMAM-PEG-EpDT3 was developed as a novel carrier for targeted delivery of IncRNA MEG3 to CRPC cells. PAMAM-PEG-EpDT3 presented more excellent targeting ability to CRPC than that without the modification of EpDT3. In addition, we elucidated the potential mechanism underlying the cellular uptake of PAMAM-PEG-EpDT3/pMEG3 NPs. In vitro and in vivo models confirmed the anti-CRPC effect of PAMAM-PEG-EpDT3/pMEG3 NPs, which indicate its great potential in gene therapy for CRPC.

\section{Methods}

\section{Materials}


Chemical reagents of analytical grade were purchased from Shanghai Lingfeng Chemical Reagent Co., Ltd (Shanghai, China). Deionized water was used throughout the experiment unless otherwise stated. Maleimide PEG3500 succinimidyl carboxymethyl ester (MAL-PEG-NHS, Mw 3500) was purchased from JenKem Technology Co., Ltd (Beijing, China). Plasmid encoding IncRNA MEG3 (pMEG3), Lipofectamine 2000, and BODIPY-493/503 NHS Ester were provided by Life Technologies (Carlsbad, CA, USA). Control pDNA was from Invitrogen (Thermo Fisher Scientific Inc., Carlsbad, CA, USA). Ethidium monoazide bromide (EMA) was abtained from Shanghai Aladdin Co., Ltd (Shanghai China). Poly (amidoamine) dendrimer (PAMAM) G5 was bought from Sigma-Aldrich (St Louis, MO, USA). Aptamer EpDT3 and Cy3 fluorescein-labeled EpDT3 with 5'-thiolation were synthesized by Guangzhou RiboBio Co., Ltd (Guangzhou, China), as described previously [16].

\section{Cell culture}

PC-3 and DU-145 cells considered to be CRPC cell lines were provided by the Chinese Academy of Sciences (Shanghai, China). The cells were cultured in RPMI 1640 medium containing 10\% fetal bovine serum (FBS), $100 \mu \mathrm{g} / \mathrm{mL}$ streptomycin, and $100 \mathrm{U} / \mathrm{mL}$ penicillin under $5 \% \mathrm{CO}_{2}$ at $37^{\circ} \mathrm{C}$ humidified atmosphere.

\section{Synthesis of PAMAM-PEG-EpDT3}

PAMAM G5 was solubilized in methyl alcohol, followed by nitrogen-drying. The PEG with two functional groups (NHS-PEG3500-MAL) was diluted in PBS (pH 8.0) to $10 \mathrm{mg} / \mathrm{mL}$. The mixture of PAMAM and NHSPEG-MAL at a molar ratio of 1:2 was stirred at room temperature for $2 \mathrm{~h}$ in the dark. The resulting mixture was concentrated two times by ultrafiltration device (MWCO $10 \mathrm{kDa}$ ) at $12000 \mathrm{rpm}$ for $20 \mathrm{~min}$ at $4{ }^{\circ} \mathrm{C}$ and resolubilized in PBS ( $\mathrm{pH}$ 7.0). The final product was lyophilized to obtain PAMAM-PEG-MAL.

The thiolated EpDT3 was coupled to MAL on the above synthesized PAMAM-PEG-MAL. Briefly, the mixture of PAMAM-PEG-MAL and thiolated EpDT3 at a molar ratio of 10:1 was stirred in a nitrogen atmosphere at room temperature for $24 \mathrm{~h}$ in the dark. Further purification was carried out by ultrafiltration to obtain PAMAM-PEG-EpDT3. The resulting synthesized product was identified by ${ }^{1} \mathrm{H}-\mathrm{NMR}$ analysis on a Varian Mercury Plus NMR 400 MHz spectrometer (Varian, Salt Lake City, UT, USA).

To obtain BODIPY-labeled PAMAM-PEG-EpDT3, BODIPY-493/503 NHS ester and PAMAM-PEG-EpDT3 (molar ratio 5:1) were mixed in $\mathrm{NaHCO}_{3}$ working solution (100 mM) and stirred at $4{ }^{\circ} \mathrm{C}$ in the dark for $12 \mathrm{~h}$. Subsequently, the unreacted BODIPY was removed by ultrafiltration device ( $\mathrm{mW} 10000)$ at $12000 \mathrm{rpm}$ for $20 \mathrm{~min}$ at $4{ }^{\circ} \mathrm{C}$. Then, the product (BODIPY-PAMAM-PEG-EpDT3) was collected and lyophilized.

\section{Evaluation of cellular uptake of PAMAM-PEG-EpDT3}

The binding capacity of EpDT3 to CRPC cells was evaluated. PC-3 and DU-145 cells were seeded in the chambered coverslips in 24-well plates at a density of $7 \times 10^{4} / \mathrm{mL}$ and cultured to $50 \%$ confluency before the culture medium was removed. Cy3-EpDT3 was added to evaluate the localization of EpDT3 in cells 
cultured for $30 \mathrm{~min}$, while those without treatment were adopted as the blank control. Subsequently, the culture medium was removed, and the cells were fixed with paraformaldehyde for 20 min. Subsequently, the nuclei were stained with Bisbenzimide Hoechst $33342(3 \mu \mathrm{g} / \mathrm{mL})$ for $15 \mathrm{~min}$. Finally, the cells were washed, and the intracellular location of EpDT3 was captured via Leica SP8 Inverted Confocal Microscope (Leica, Heidelberg, Germany) under $\times 100$ magnification.

Fluorescence microscopy was used to evaluate the cellular uptake of PAMAM-PEG-EpDT3 by PC-3 and DU-145 cells in a concentration-dependent manner. The cells were seeded in 24-well plates at a density of $7 \times 10^{4} / \mathrm{mL}$ and cultured to $90 \%$ confluency. Then, BODIPY-PAMAM-PEG-EpDT3 at the PAMAM concentrations of $0.05,0.1,0.2,0.5$, and $1 \mu \mathrm{M}$ was added to the culture medium. The cells were incubated for 30 min, washed three times with PBS, and observed with IX53 Inverted Fluorescence Microscope (Olympus, Tokyo, Japan) to evaluate the cellular uptake of PAMAM-PEG-EpDT3.

Flow cytometry was also used to study the cellular uptake of PAMAM-PEG-EpDT3 in PC-3 and DU-145 cells. The cells were seeded in 6-well plates at a density of $2 \times 10^{5} / \mathrm{mL}$ and cultured to $90 \%$ confluency. Then BODIPY-PAMAM-PEG-EpDT3 or BODIPY-PAMAM was added at the concentration of $0.5 \mu \mathrm{M}$. After incubation for $30 \mathrm{~min}$, the cells were washed, trypsinized, and resuspended in $200 \mu \mathrm{L} \mathrm{PBS} \mathrm{(pH} \mathrm{7.0).} \mathrm{The}$ fluorescence intensity of BODIPY was measured using a flow cytometer (NovoCyte, ACEA Biosciences Inc., Hangzhou, China) to determine the cellular uptake. The cells without treatment were used as negative control.

\section{Preparation of PAMAM-PEG-EpDT3/pMEG3 NPs}

The plasmid encoding IncRNA MEG3 (pMEG3) was chosen to construct PAMAM-PEG-EpDT3/pMEG3 NPs to investigate the inhibitory effect of CRPC cells. pMEG3 was diluted to $100 \mu \mathrm{g} / \mathrm{mL}$ with $50 \mathrm{mM} \mathrm{Na} \mathrm{SO}_{4}$, which was mixed with newly synthesized PAMAM, PAMAM-PEG, and PAMAM-PEG-EpDT3 at different phosphorus (N/P) ratio for $30 \mathrm{~s}$ and incubated at room temperature for $30 \mathrm{~min}$.

\section{Characterization of PAMAM-PEG-EpDT3/pMEG3 NPs}

The particle size of PAMAM-PEG-EpDT3/pMEG3 was measured through dynamic light scattering (DLS), and zeta potential was measured by electrophoretic light scattering (ELS) via Zetasizer Nano ZS90 particle size and zeta potential analyzer (Malvern Panalytical, Malvern, UK).

Agarose gel electrophoresis was performed to evaluate the encapsulation efficiency of PAMAM-PEGEpDT3. Samples of PAMAM/pMEG3, PAMAM-PEG/pMEG3, and PAMAM-PEG-EpDT3/pMEG3 at the N/P ratio of $1,5,10,15,20$ were resolved by agarose gel electrophoresis $(0.5 \%)$ and visualized by Gelview staining. The naked pMEG3 and $1 \mathrm{kbp}$ DNA ladder served as controls.

\section{Endocytosis inhibition study}

Ethidium monoazide bromide (EMA) was used to label the plasmid vector pMEG3, according to the manufacturer's protocol. In order to elucidate the mechanism underlying the cellular uptake, PC-3 cells 
were seeded on the coverslips in 24-well plates at a density of $7 \times 10^{4} / \mathrm{mL}$ and cultured to $90 \%$ confluency. Endocytosis inhibitors, such as filipin (inhibitor of caveolin-mediated endocytosis), phenylarsine oxide (inhibitor of clathrin-mediated endocytosis), and colchicine (inhibitor of macropinocytosis), were added to the culture medium, respectively. After 30 min pre-treatment, the cells were incubated with a new culture medium containing BODIPY-PAMAM-PEG-EpDT3 (equivalent to $1 \mu \mathrm{M}$ PAMAM) for an additional $30 \mathrm{~min}$. In order to assess if the uptake was energy-dependent, the cells were incubated with BODIPY-PAMAM-PEG-EPDT3 at $4{ }^{\circ} \mathrm{C}$ for $30 \mathrm{~min}$. To investigate the specificity of the cellular uptake of PAMAM-PEG-EpDT3, PC-3 cells were pretreated with $10 \mu \mathrm{M}$ EpDT3 for 30 min to saturate the EpCAM receptor, followed by washing with PBS and examination by fluorescence microscopy.

Moreover, the subsequent steps were carried out as described above to investigate the cellular uptake of PAMAM-PEG-EpDT3/EMA-pMEG3.

\section{Cytotoxicity assays in vitro}

The cytotoxicity of PAMAM and PAMAM-PEG-EpDT3 vehicles was studied to determine its safety by CCK$8 \mathrm{kit}$, according to the manufacturer's instructions. PC-3 cells were seeded in 96-well plates at a density of $8 \times 10^{3}$ cells/well and cultured for $24 \mathrm{~h}$. The culture medium was replaced with PAMAM and PAMAM-PEGEpDT3 at the concentration of $20,100,200,300$, and $400 \mu \mathrm{g} / \mathrm{mL}$. After incubation for $24 \mathrm{~h}, 10 \mu \mathrm{L}$ of CCK8 was added to each well and incubated for an additional $1 \mathrm{~h}$. Subsequently, the absorbance was measured at $450 \mathrm{~nm}$ using Spectra Max M2 Multiskan Spectrum Microplate (Molecular Devices, Sunnyvill, CA, USA). The cell viability was calculated using the following formula: Survival $\%=(A 450 \mathrm{~nm}$ of treated cells - A450 nm of blank) / (A450 nm of control cells - A450 nm of blank) $\times 100 \%$, where the A450 $\mathrm{nm}$ represents the absorbance value. Each assay was repeated six times.

The in vitro anti-CPRC effect of PAMAM-PEG-EpDT3/pMEG3 was also determined by the CCK-8 assay, as described above. PAMAM-PEG-EpDT3/pMEG3 and PAMAM-PEG/pMEG3 (N/P = 15) were added to PC-3 cells at the pMEG3 concentration of $0.02,0.05,0.1,0.3,0.6,1,3,9,30 \mu \mathrm{M}$, respectively. After $48-\mathrm{h}$ incubation, CCK-8 assay was performed as described above.

\section{In vivo antitumor study}

BALB/c male nude mice (4-weeks-old) were purchased from Shanghai SLAC Laboratory Animal Co., Ltd and maintained in a specific pathogen-free (SPF) environment. All animal experiments complied with the standard operating procedures approved by the animal ethics committee. To establish a tumor bearing mouse model, $10^{7}$ PC-3 cells in $200 \mu \mathrm{L}$ PBS were injected into nude mice subcutaneously on the right back of the hind leg. The CRPC model was used when tumor volume reached approximately $100 \mathrm{~mm}^{3}$.

Twenty nude mice with PC-3 cell xenograft tumors of uniform shape and size were randomly divided into four groups (5 mice per group) and treated with A) PBS, B) PAMAM-PEG-EpDT3/pDNA, C) PAMAMPEG/pMEG3, and D) PAMAM-PEG-EpDT3/pMEG3, respectively. The injection was administered on days 
$1,3,5,7$, and 9 at a dose of $2.5 \mathrm{mg} / \mathrm{kg}$ pDNA or PMEG3, followed by observation for 10 days. The bodyweight of the mice were monitored every 2 days. Subsequently, the mice were sacrificed, the tumors and vital organs were excised for analysis. In addition, $1.5 \mathrm{ml}$ whole blood was taken to measure ALT, AST and CRE.

\section{Histological analysis}

Tumor tissues were fixed with $4 \%$ paraformaldehyde for $24 \mathrm{~h}$. After dehydration with alcohol gradient, the tumor tissues were embedded in paraffin, sliced into 4- $\mu$ m-thick sections, dewaxed, and stained with H\&E. Images were acquired using a Nikon (Tokyo, Japan) Eclipse Cl microscope equipped with DS-U3 imaging system for histopathological evaluation.

The expression of proteins Ki67, Bcl-2, Cyclin D1, and P53 proteins in tumor tissues was detected by immunohistochemistry by an experienced pathologist.

\section{Statistical analysis}

SPSS 18.0 software was adopted for statistical analysis, and data are presented as mean \pm SD. One-way analysis of variance (ANOVA) was used to analyze the significance between groups. $P<0.05$ indicated a significant difference.

\section{Abbreviations}

CRPC: castration-resistant prostate cancer; NPs: nanoparticles; PCa: prostate cancer; PAMAM: poly (amidoamine) dendrimer; IncRNA: long noncoding RNA; ncRNA: Noncoding RNA; pMEG3: plasmidencoding IncRNA MEG3; ${ }^{1} \mathrm{H}-\mathrm{NMR}:{ }^{1} \mathrm{H}$-nuclear paramagnetic resonance; HPLC: high-pressure liquid chromatography; PBS: phosphate buffer solution; PEG: polyethylene glycol; MAL: maleimide; PDNA: plasmid DNA; CLSM: confocal laser scanning microscopy; AST: Aspartate transferase; ALT: glutamic acid alanine transferase; CR: creatinine; H\&E: hematoxylin and eosin; IHC: immunohistochemistry; NHS: succinimide.

\section{Declarations}

\section{Acknowledgements}

Not applicable.

\section{Corresponding Author}

*qgzhu@126.com (Quangang Zhu)

*aajian818@163.com (Zhongjian Chen)

\section{Author Contributions}


The manuscript was written through contributions of all authors. All authors have given approval to the final version of the manuscript. Zongguang Tai, Jinyuan Ma, Jianing Ding contributed equally.

\section{Funding}

This work was supported by the National Natural Science Foundation of China (81472394 and 81803078) and the Key Discipline Construction Project and Doctoral Supervisor Candidate of Shanghai Skin Disease Hospital (2019zdxk03, 17HBDS02, and 17HBDS03).

\section{Availability of data and materials}

All dates generated and analyzed during this study are included in this paper.

\section{Ethics approval and consent to participate}

Compliance with ethical guidelines.

\section{Conflict of interest}

The authors declare that they have no conflict of interest.

\section{References}

1. Eastham JA, Heller G, Halabi S, Monk JP, 3rd, Beltran H, Gleave M, Evans CP, Clinton SK, Szmulewitz RZ, Coleman J, et al: Cancer and Leukemia Group B 90203 (Alliance): Radical Prostatectomy With or Without Neoadjuvant Chemohormonal Therapy in Localized, High-Risk Prostate Cancer. J Clin Oncol 2020:Jco2000315.

2. Parker C, Castro E, Fizazi K, Heidenreich A, Ost P, Procopio G, Tombal B, Gillessen S: Prostate Cancer: ESMO Clinical Practice Guidelines for diagnosis, treatment and follow-up. Ann Oncol 2020.

3. Perera M, Roberts MJ, Klotz L, Higano CS, Papa N, Sengupta S, Bolton D, Lawrentschuk N: Intermittent versus continuous androgen deprivation therapy for advanced prostate cancer. Nat Rev Urol 2020, 17:469-481.

4. Gjyrezi A, Xie F, Voznesensky O, Khanna P, Calagua C, Bai Y, Kung J, Wu J, Corey E, Montgomery B, et al: Taxane resistance in prostate cancer is mediated by decreased drug-target engagement. $\mathrm{J}$ Clin Invest 2020, 130:3287-3298.

5. Sternberg CN, Fizazi K, Saad F, Shore ND, De Giorgi U, Penson DF, Ferreira U, Efstathiou E, Madziarska $\mathrm{K}$, Kolinsky MP, et al: Enzalutamide and Survival in Nonmetastatic, Castration-Resistant Prostate Cancer. N Engl J Med 2020, 382:2197-2206.

6. van Haasteren J, Li J, Scheideler OJ, Murthy N, Schaffer DV: The delivery challenge: fulfilling the promise of therapeutic genome editing. Nat Biotechno/2020, 38:845-855.

7. Ma CC, Wang ZL, Xu T, He ZY, Wei YQ: The approved gene therapy drugs worldwide: from 1998 to 2019. Biotechnol Adv 2020, 40:107502. 
8. Maetzel D, Denzel S, Mack B, Canis M, Went P, Benk M, Kieu C, Papior P, Baeuerle PA, Munz M, Gires O: Nuclear signalling by tumour-associated antigen EpCAM. Nat Cell Biol 2009, 11:162-171.

9. Gires O, Pan M, Schinke H, Canis M, Baeuerle PA: Expression and function of epithelial cell adhesion molecule EpCAM: where are we after 40 years? Cancer Metastasis Rev 2020.

10. Ni J, Cozzi P, Hao J, Beretov J, Chang L, Duan W, Shigdar S, Delprado W, Graham P, Bucci J, et al: Epithelial cell adhesion molecule (EpCAM) is associated with prostate cancer metastasis and chemo/radioresistance via the PI3K/Akt/mTOR signaling pathway. Int J Biochem Cell Biol 2013, 45:2736-2748.

11. Gupta S, Li J, Kemeny G, Bitting RL, Beaver J, Somarelli JA, Ware KE, Gregory S, Armstrong AJ: Whole Genomic Copy Number Alterations in Circulating Tumor Cells from Men with Abiraterone or Enzalutamide-Resistant Metastatic Castration-Resistant Prostate Cancer. Clin Cancer Res 2017, 23:1346-1357.

12. Ni J, Cozzi PJ, Duan W, Shigdar S, Graham PH, John KH, Li Y: Role of the EpCAM (CD326) in prostate cancer metastasis and progression. Cancer Metastasis Rev 2012, 31:779-791.

13. Ptacek J, Zhang D, Qiu L, Kruspe S, Motlova L, Kolenko P, Novakova Z, Shubham S, Havlinova B, Baranova $P$, et al: Structural basis of prostate-specific membrane antigen recognition by the A9g RNA aptamer. Nucleic Acids Res 2020.

14. He XY, Ren XH, Peng Y, Zhang JP, Ai SL, Liu BY, Xu C, Cheng SX: Aptamer/Peptide-Functionalized Genome-Editing System for Effective Immune Restoration through Reversal of PD-L1-Mediated Cancer Immunosuppression. Adv Mater 2020, 32:e2000208.

15. Tan W, Li L, Xu S, Yan H, Li X, Yazd HS, Li X, Huang T, Cui C, Jiang J: Nucleic Acid Aptamers for Molecular Diagnostics and Therapeutics: Advances and Perspectives. Angew Chem Int Ed Eng/2020.

16. Shigdar S, Lin J, Yu Y, Pastuovic M, Wei M, Duan W: RNA aptamer against a cancer stem cell marker epithelial cell adhesion molecule. Cancer Sci 2011, 102:991-998.

17. Xiang D, Shigdar S, Bean AG, Bruce M, Yang W, Mathesh M, Wang T, Yin W, Tran PH, Al Shamaileh H, et al: Transforming doxorubicin into a cancer stem cell killer via EpCAM aptamer-mediated delivery. Theranostics 2017, 7:4071-4086.

18. Wolin SL, Maquat LE: Cellular RNA surveillance in health and disease. Science 2019, 366:822-827.

19. Revia RA, Stephen ZR, Zhang M: Theranostic Nanoparticles for RNA-Based Cancer Treatment. Acc Chem Res 2019, 52:1496-1506.

20. Yao RW, Wang Y, Chen LL: Cellular functions of long noncoding RNAs. Nat Cell Biol 2019, 21:542551.

21. Peng W, Si S, Zhang Q, Li C, Zhao F, Wang F, Yu J, Ma R: Long non-coding RNA MEG3 functions as a competing endogenous RNA to regulate gastric cancer progression. J Exp Clin Cancer Res 2015, 34:79.

22. Uroda T, Anastasakou E, Rossi A, Teulon JM, Pellequer JL, Annibale P, Pessey O, Inga A, Chillón I, Marcia M: Conserved Pseudoknots in IncRNA MEG3 Are Essential for Stimulation of the p53 Pathway. Mol Cell 2019, 75:982-995.e989. 
23. Shihabudeen Haider Ali MS, Cheng X, Moran M, Haemmig S, Naldrett MJ, Alvarez S, Feinberg MW, Sun X: LncRNA Meg3 protects endothelial function by regulating the DNA damage response. Nucleic Acids Res 2019, 47:1505-1522.

24. Luo G, Wang M, Wu X, Tao D, Xiao X, Wang L, Min F, Zeng F, Jiang G: Long Non-Coding RNA MEG3 Inhibits Cell Proliferation and Induces Apoptosis in Prostate Cancer. Cell Physiol Biochem 2015, 37:2209-2220.

25. Wahlestedt C: Targeting long non-coding RNA to therapeutically upregulate gene expression. Nat Rev Drug Discov 2013, 12:433-446.

26. Huarte M: The emerging role of IncRNAs in cancer. Nat Med 2015, 21:1253-1261.

27. Wu P, Mo Y, Peng M, Tang T, Zhong Y, Deng X, Xiong F, Guo C, Wu X, Li Y, et al: Emerging role of tumor-related functional peptides encoded by IncRNA and circRNA. Mol Cancer 2020, 19:22.

28. Wang G, Zhou Z, Zhao Z, Li Q, Wu Y, Yan S, Shen Y, Huang P: Enzyme-Triggered Transcytosis of Dendrimer-Drug Conjugate for Deep Penetration into Pancreatic Tumors. ACS Nano 2020, 14:48904904.

29. Li HJ, Liu J, Luo YL, Chen SB, Liu R, Du JZ, Wang J: Intratumor Performance and Therapeutic Efficacy of PAMAM Dendrimers Carried by Clustered Nanoparticles. Nano Lett 2019, 19:8947-8955.

30. Guo X, Wang L, Duval K, Fan J, Zhou S, Chen Z: Dimeric Drug Polymeric Micelles with Acid-Active Tumor Targeting and FRET-Traceable Drug Release. Adv Mater 2018, 30.

31. Gao F, Tang Y, Liu WL, Zou MZ, Huang C, Liu CJ, Zhang XZ: Intra/Extracellular Lactic Acid Exhaustion for Synergistic Metabolic Therapy and Immunotherapy of Tumors. Adv Mater 2019, 31:e1904639.

32. He J, Li C, Ding L, Huang Y, Yin X, Zhang J, Zhang J, Yao C, Liang M, Pirraco RP, et al: Tumor Targeting Strategies of Smart Fluorescent Nanoparticles and Their Applications in Cancer Diagnosis and Treatment. Adv Mater 2019, 31:e1902409.

33. Al-Ahmady ZS, Jasim D, Ahmad SS, Wong R, Haley M, Coutts G, Schiessl I, Allan SM, Kostarelos K: Selective Liposomal Transport through Blood Brain Barrier Disruption in Ischemic Stroke Reveals Two Distinct Therapeutic Opportunities. ACS Nano 2019, 13:12470-12486.

34. Wang T, Zhang J, Hou T, Yin X, Zhang N: Selective targeting of tumor cells and tumor associated macrophages separately by twin-like core-shell nanoparticles for enhanced tumor-localized chemoimmunotherapy. Nanoscale 2019, 11:13934-13946.

35. Robertson JFR, Coleman RE, Cheung KL, Evans A, Holcombe C, Skene A, Rea D, Ahmed S, Jahan A, Horgan K, et al: Proliferation and AKT Activity Biomarker Analyses after Capivasertib (AZD5363) Treatment of Patients with ER(+) Invasive Breast Cancer (STAKT). Clin Cancer Res 2020, 26:15741585.

36. Lawrence MG, Obinata D, Sandhu S, Selth LA, Wong SQ, Porter LH, Lister N, Pook D, Pezaro CJ, Goode DL, et al: Patient-derived Models of Abiraterone- and Enzalutamide-resistant Prostate Cancer Reveal Sensitivity to Ribosome-directed Therapy. Eur Urol 2018, 74:562-572.

37. Ellis MJ, Suman VJ, Hoog J, Goncalves R, Sanati S, Creighton CJ, DeSchryver K, Crouch E, Brink A, Watson M, et al: Ki67 Proliferation Index as a Tool for Chemotherapy Decisions During and After 
Neoadjuvant Aromatase Inhibitor Treatment of Breast Cancer: Results From the American College of Surgeons Oncology Group Z1031 Trial (Alliance). J Clin Oncol 2017, 35:1061-1069.

38. García-Sáez AJ: The BCL-2 family saga. Nat Rev Mol Cell Biol 2020.

39. Delbridge AR, Grabow S, Strasser A, Vaux DL: Thirty years of BCL-2: translating cell death discoveries into novel cancer therapies. Nat Rev Cancer 2016, 16:99-109.

40. Ashkenazi A, Fairbrother WJ, Leverson JD, Souers AJ: From basic apoptosis discoveries to advanced selective BCL-2 family inhibitors. Nat Rev Drug Discov 2017, 16:273-284.

41. Yu Z, Wang L, Wang C, Ju X, Wang M, Chen K, Loro E, Li Z, Zhang Y, Wu K, et al: Cyclin D1 induction of Dicer governs microRNA processing and expression in breast cancer. Nat Commun 2013, 4:2812.

42. Shan J, Zhao W, Gu W: Suppression of cancer cell growth by promoting cyclin D1 degradation. Mol Cell 2009, 36:469-476.

43. Kim Y, Jin D, Lee BB, Cho EY, Han J, Shim YM, Kim HK, Kim DH: Overexpression of $\beta$-Catenin and Cyclin D1 is Associated with Poor Overall Survival in Patients with Stage IA-IIA Squamous Cell Lung Cancer Irrespective of Adjuvant Chemotherapy. J Thorac Oncol 2016, 11:2193-2201.

44. Duffy MJ, Synnott NC, O'Grady S, Crown J: Targeting p53 for the treatment of cancer. Semin Cancer Biol 2020.

45. Zhang C, Liu J, Xu D, Zhang T, Hu W, Feng Z: Gain-of-function mutant p53 in cancer progression and therapy. J Mol Cell Biol 2020.

46. Moreira AL, Won HH, McMillan R, Huang J, Riely GJ, Ladanyi M, Berger MF: Massively parallel sequencing identifies recurrent mutations in TP53 in thymic carcinoma associated with poor prognosis. J Thorac Oncol 2015, 10:373-380.

47. Dibra D, Mitra A, Newman M, Xia X, Cutrera JJ, Gagea M, Kleinerman ES, Lozano G, Li S: Lack of Immunomodulatory Interleukin-27 Enhances Oncogenic Properties of Mutant p53 In Vivo. Clin Cancer Res 2016, 22:3876-3883.

48. Yemelyanova A, Vang R, Kshirsagar M, Lu D, Marks MA, Shih le M, Kurman RJ: Immunohistochemical staining patterns of p53 can serve as a surrogate marker for TP53 mutations in ovarian carcinoma: an immunohistochemical and nucleotide sequencing analysis. Mod Pathol 2011, 24:1248-1253.

\section{Figures}




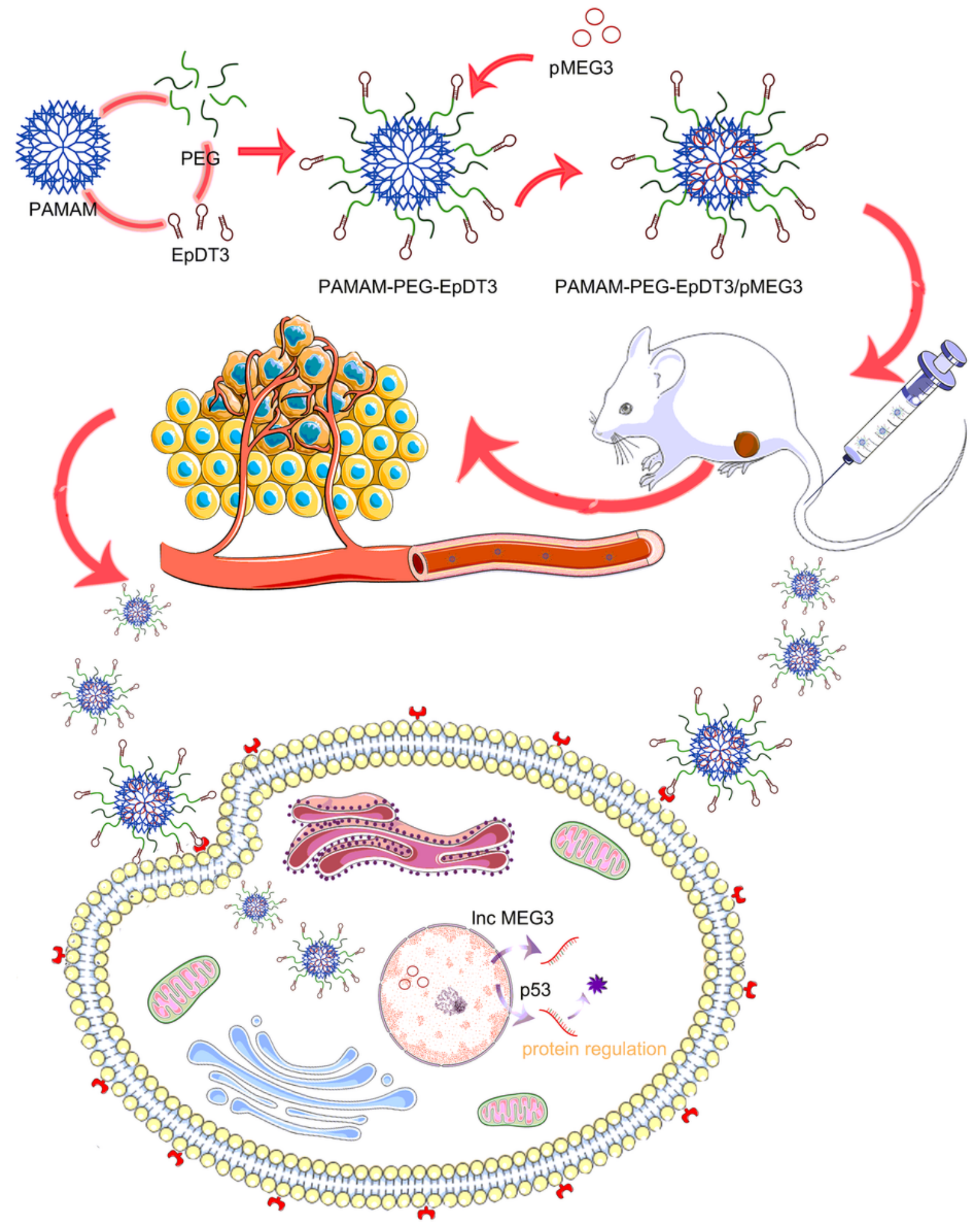

\section{Figure 1}

Schematic illustration of the anti-CRPC effect of PAMAM-PEG-EpDT3/pMEG3 NPs. 

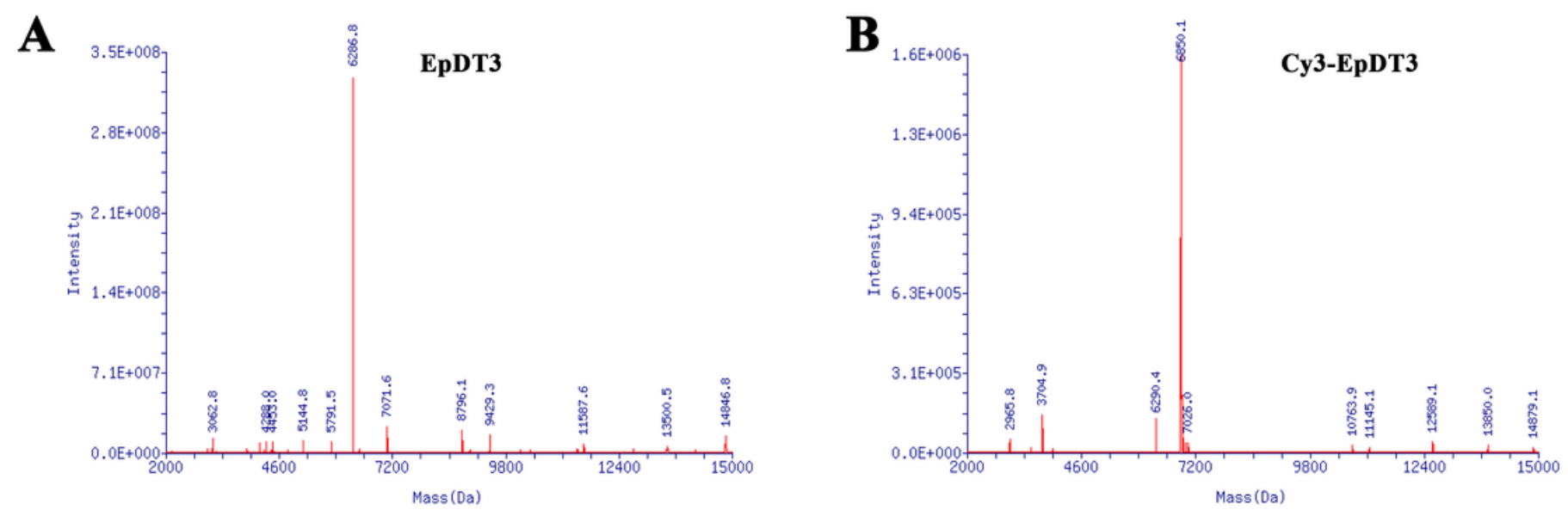

C<smiles>CC(C)(CNCCCN1C(=O)C=CC1=O)COC(=O)C(C)(C)ON1C(=O)CCC1=O</smiles>

D

PAMAM Dendrimers $\mathrm{G}=5$ with $128 \mathrm{NH}_{2}$ Surface Groups

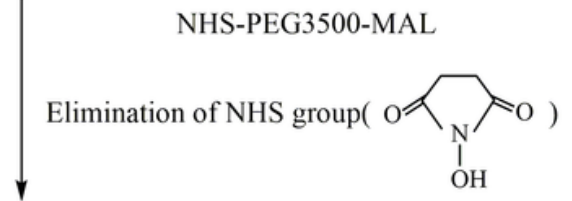

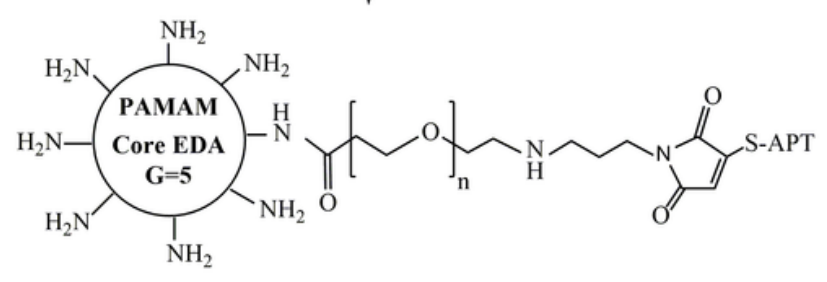

PAMAM-PEG-EpDT3
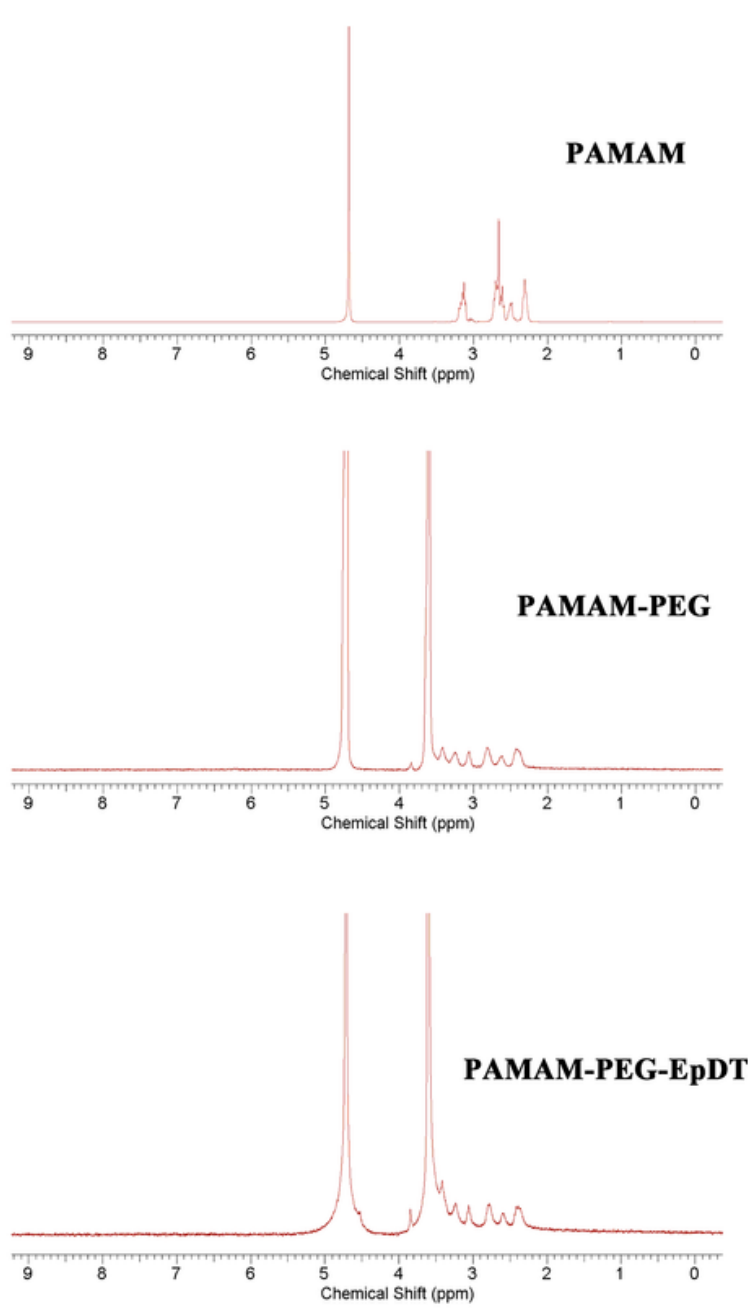

Figure 2

(A) Mass spectrometry report of thiol-EpDT3 and (B) Cy3-EpDT3. (C) Synthesis of PAMAM-PEG-EpDT3.

(D) $1 \mathrm{H}-\mathrm{NHM}$ spectra of PAMAM, PEG, PAMAM-PEG, and PAMAM-PEG-EpDT3. 
$\mathbf{A}$

N/P Ratio

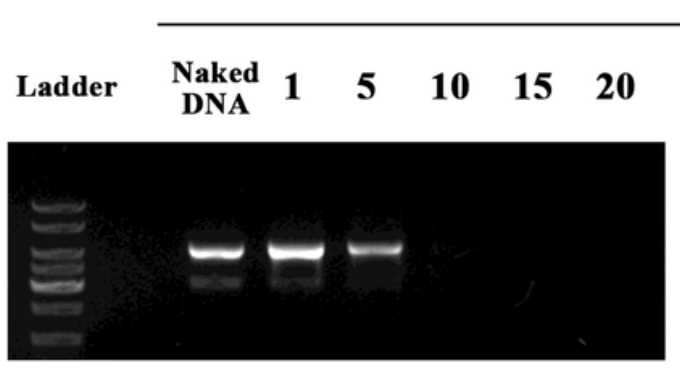

PAMAM/pMEG3

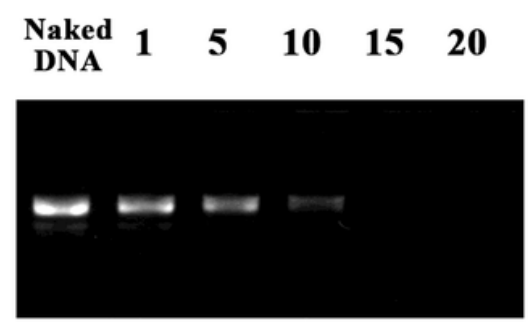

PAMAM-PEG/pMEG3 $\begin{array}{lllll}1 & 5 & 10 & 15 & 20\end{array}$

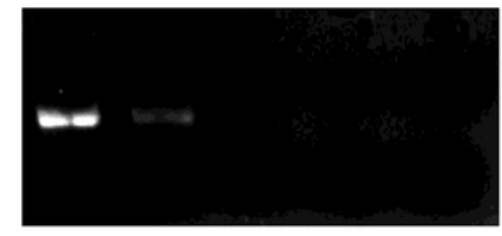

PAMAM-PEG-EpDT3/pMEG3
B

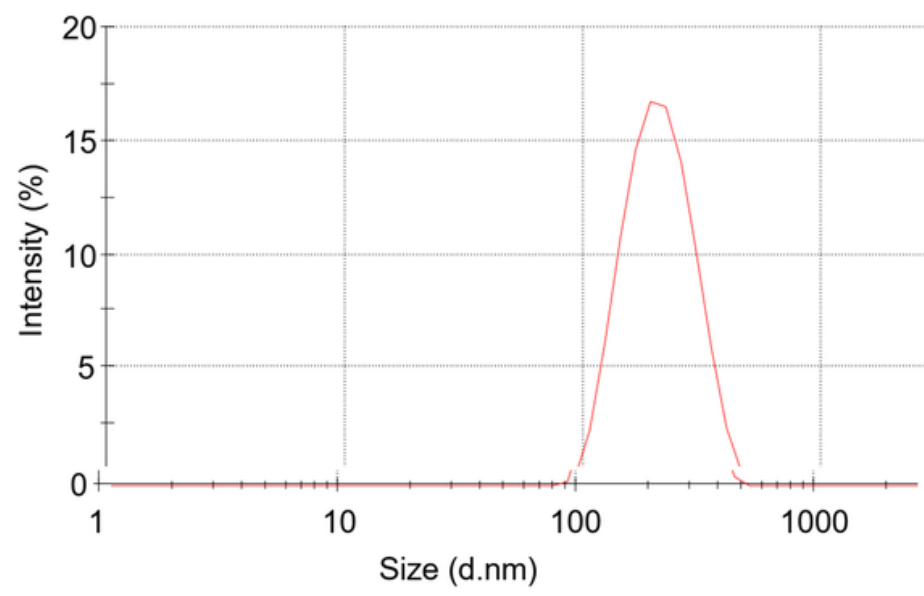

C

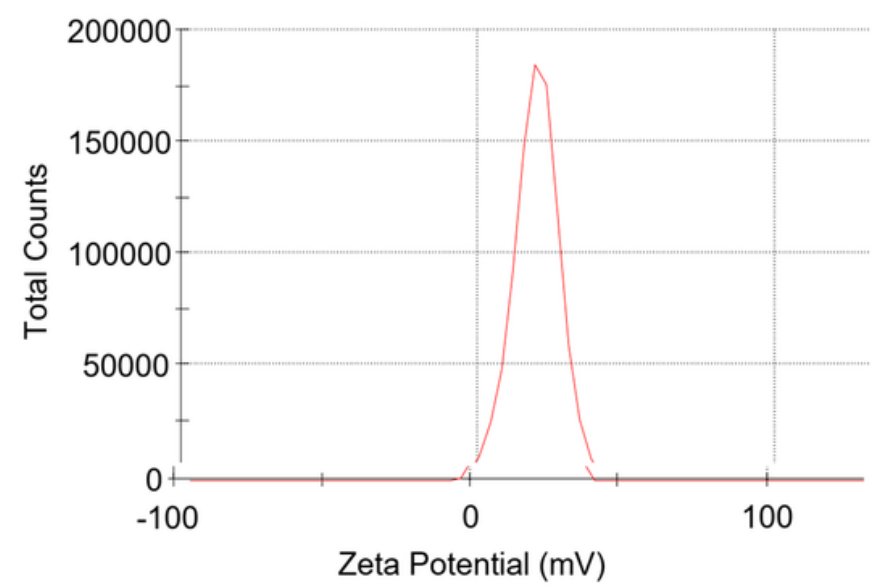

Figure 3

(A) Agarose gel electrophoresis assay of PAMAM/pMEG3, PAMAM-PEG/pMEG3, and PAMAM-PEGEpDT3/pMEG3 complexes at different N/P ratios. (B) Size distribution of PAMAM-PEG-EpDT3/pMEG3 complexes at N/P=15 was estimated by DLS and (C) zeta potential distribution of PAMAM-PEGEpDT3/pMEG3 complexes at N/P=15 by ELS. 
$\mathbf{A}$

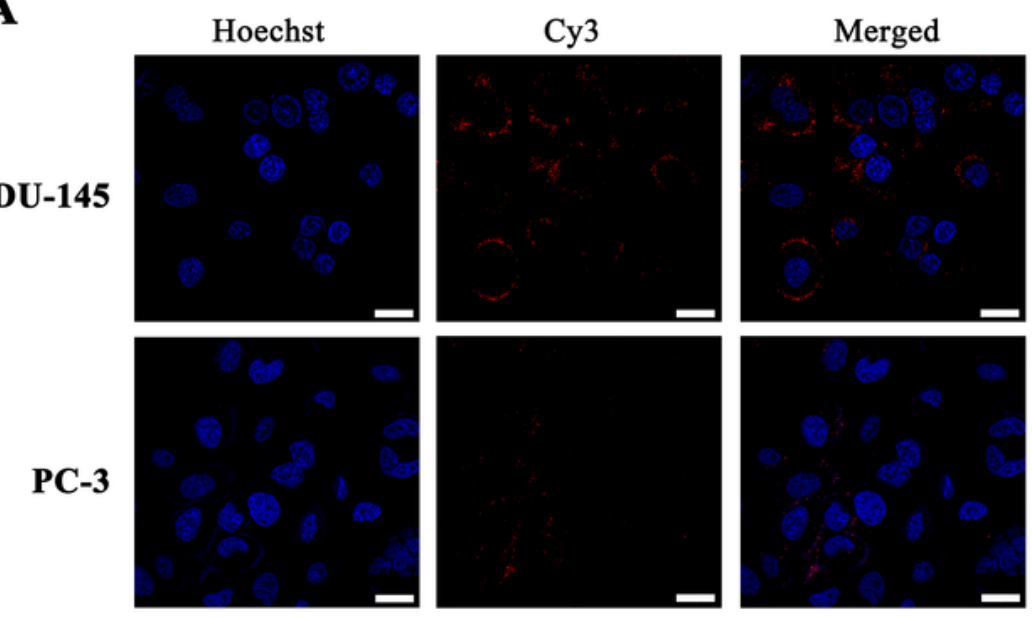

B
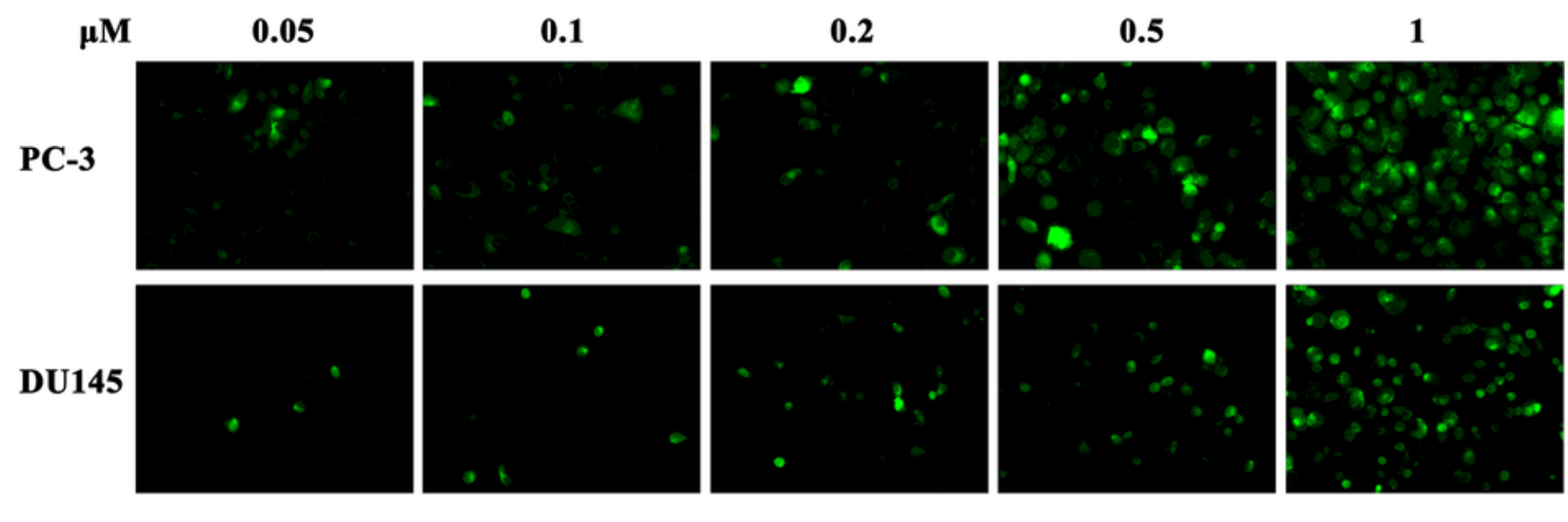

C

Control

BODIPY-PAMAM

- BODIPY-PAMAM-PEG-EpDT3
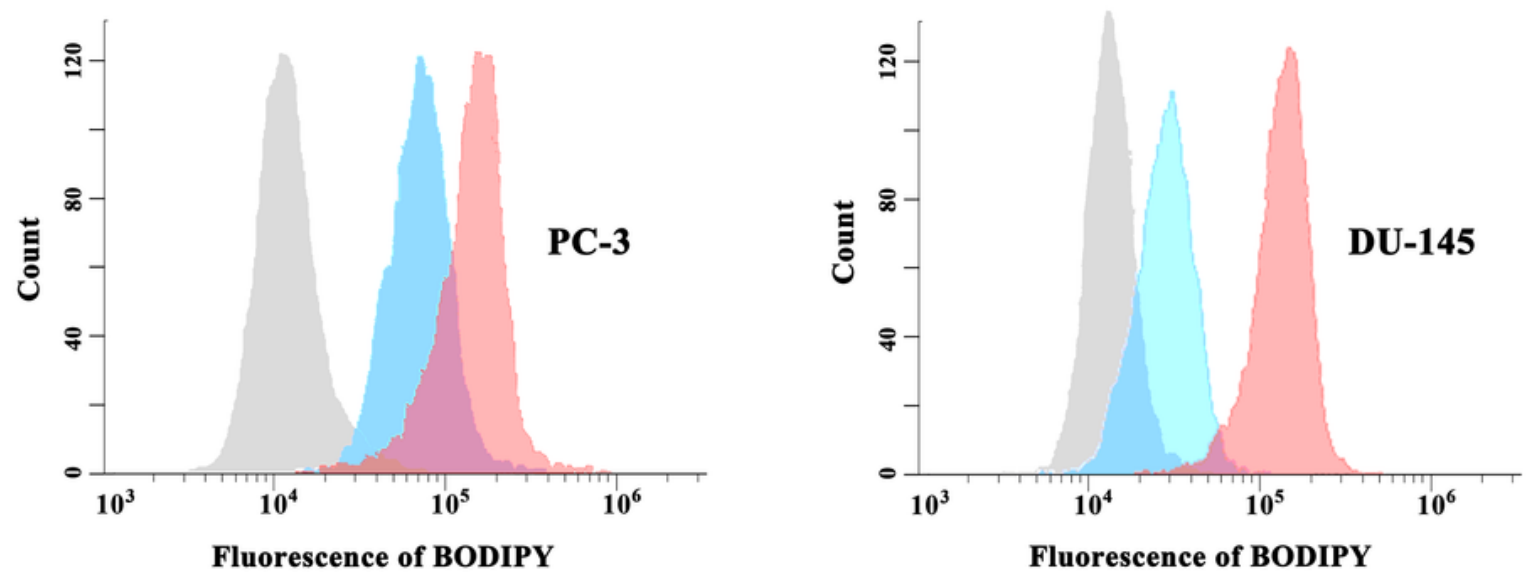

Figure 4

(A) Evaluation of Cy3-EpDT3 targeting PC-3 and DU-145 cells. Blue: Hoechst, Red: Cy3-EpDT3. Scale bar represents $25 \mu \mathrm{m}$. (B) Cellular uptake of BODIPY-PAMAM-PEG-EpDT3 at the concentration of 0.05, 0.1, $0.2,0.5$, and $1 \mu \mathrm{M}$ in PC-3 and DU-145 cells after 30 min incubation. Original magnification: $\times 100$. (C) BODIPY-positive PC-3 and DU-145 cells detected by flow cytometry after treatment by BODIPY-PAMAM and BODIPY-PAMAM-PEG-EPDT3. 
A Control
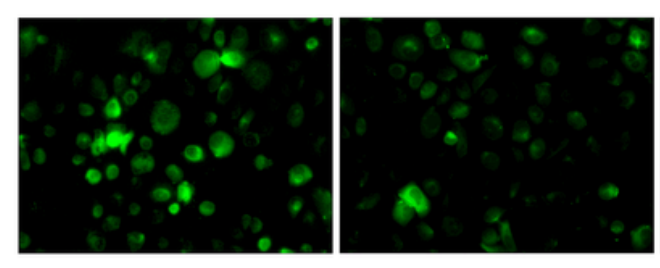

B
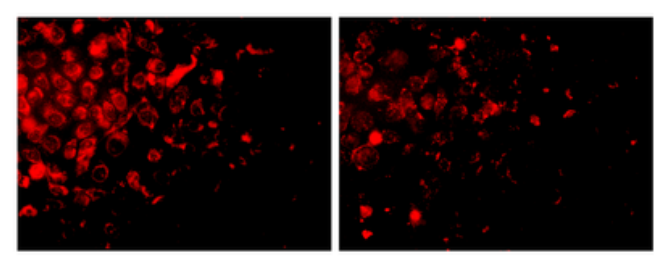

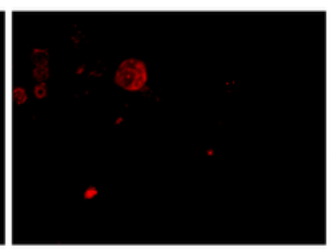

Phenylarsine oxide
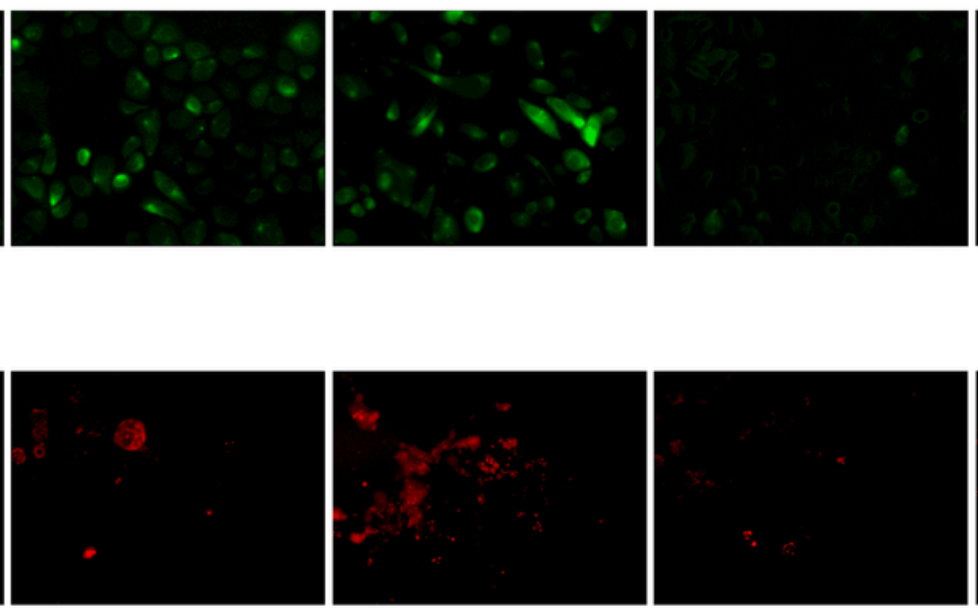

EpDT3 block
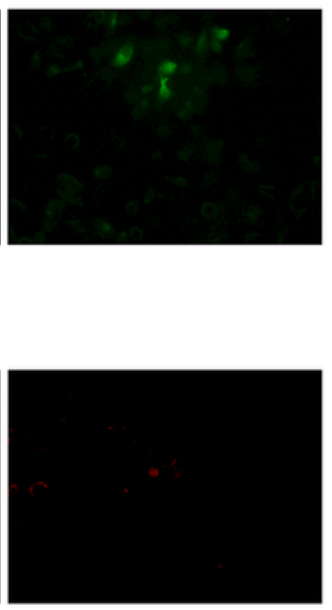

\section{Figure 5}

(A) Mechanism of the endocytosis of BODIPY-PAMAM-PEG-EpDT3 in PC-3 cells. Green fluorescence: BODIPY. Original magnification: $\times 100$. (B) Mechanism of the endocytosis of PAMAM-PEG-EpDT3/pMEG3 in PC-3 cells. Red fluorescence: EMA-pMEG3. Original magnification: $\times 100$. 
$\mathbf{A}$

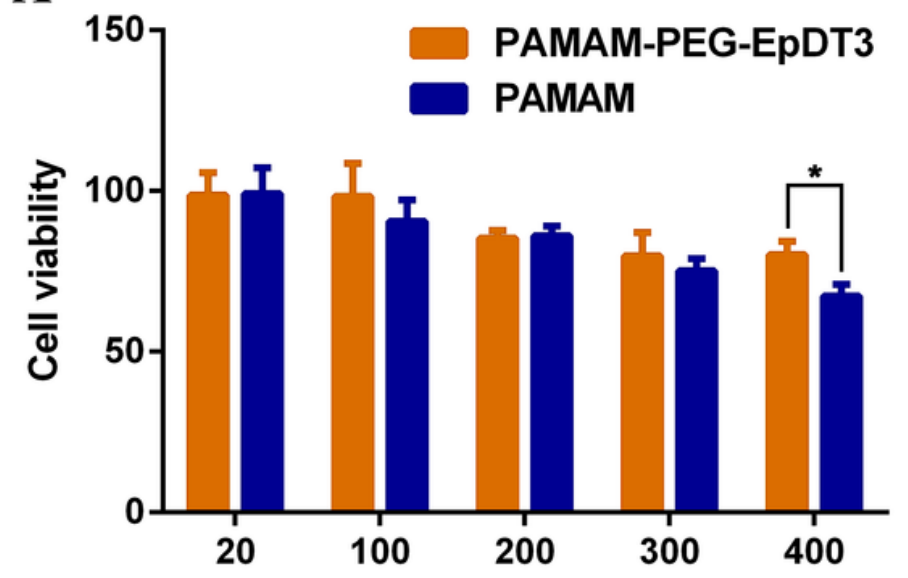

Concentration of PAMAM $(\mu \mathrm{g} / \mathrm{mL})$

C

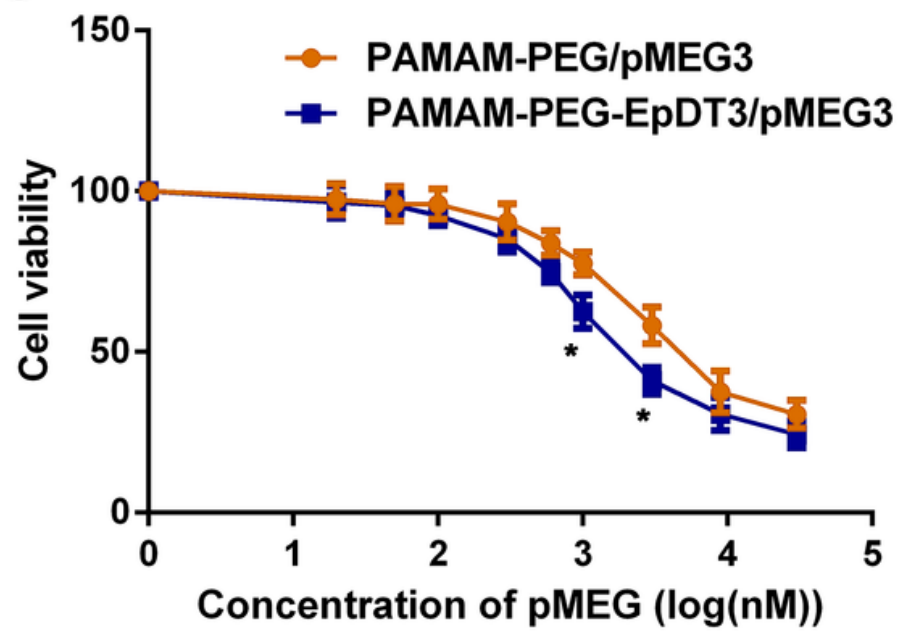

B

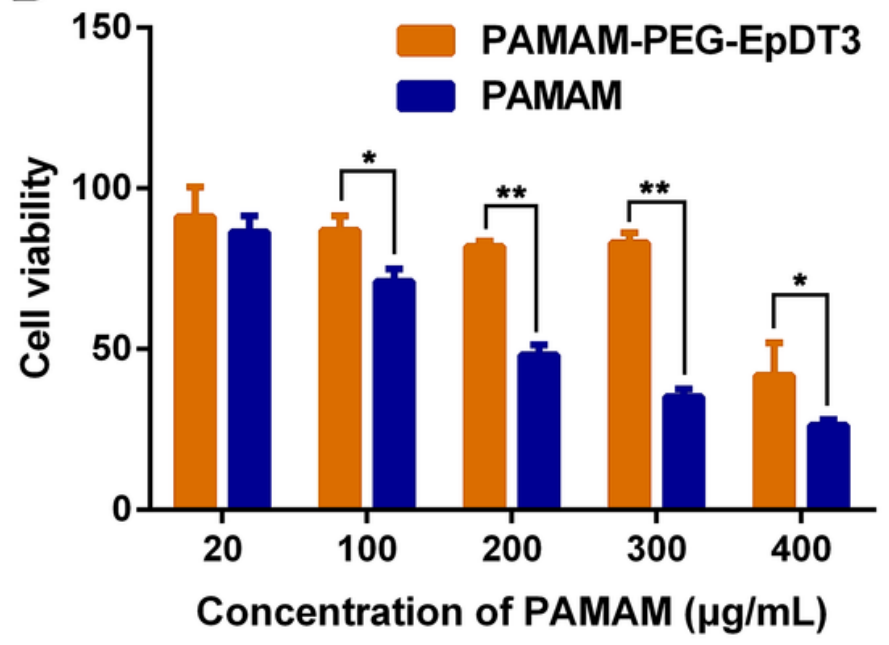

D

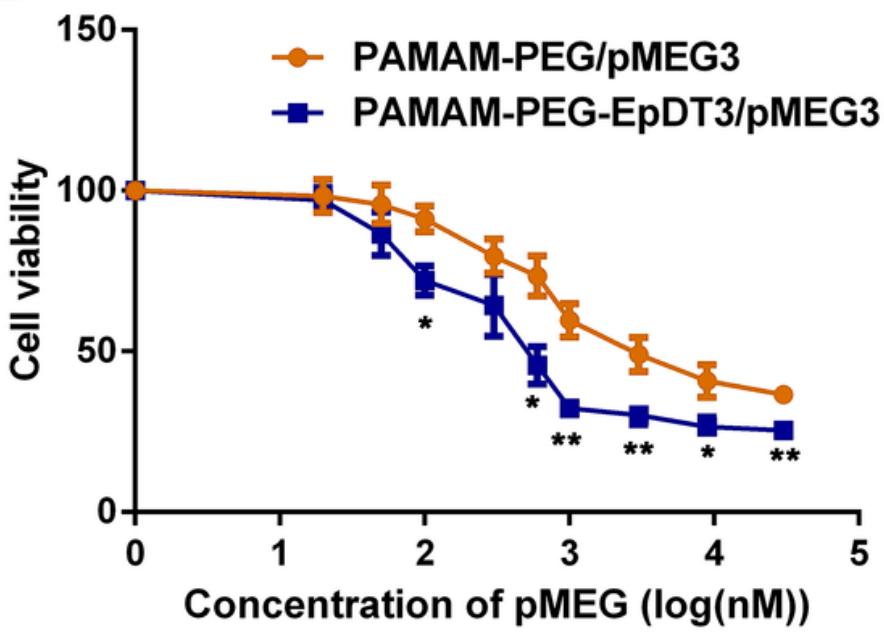

Figure 6

Cell viability of (A) PC-3 and (B) DU-145 cells incubated with PAMAM and PAMAM-PEG-EpDT3 for $4 \mathrm{~h}$. Cell viability of (C) PC-3 and (D) DU-145 cells treated with PAMAM-PEG-EpDT3/pMEG3 and PAMAM$P E G / p M E G 3$ complexes. Data represented mean $\pm S D(n=6)$. ${ }^{*}<<0.05,{ }^{*} * P<0.01$. 

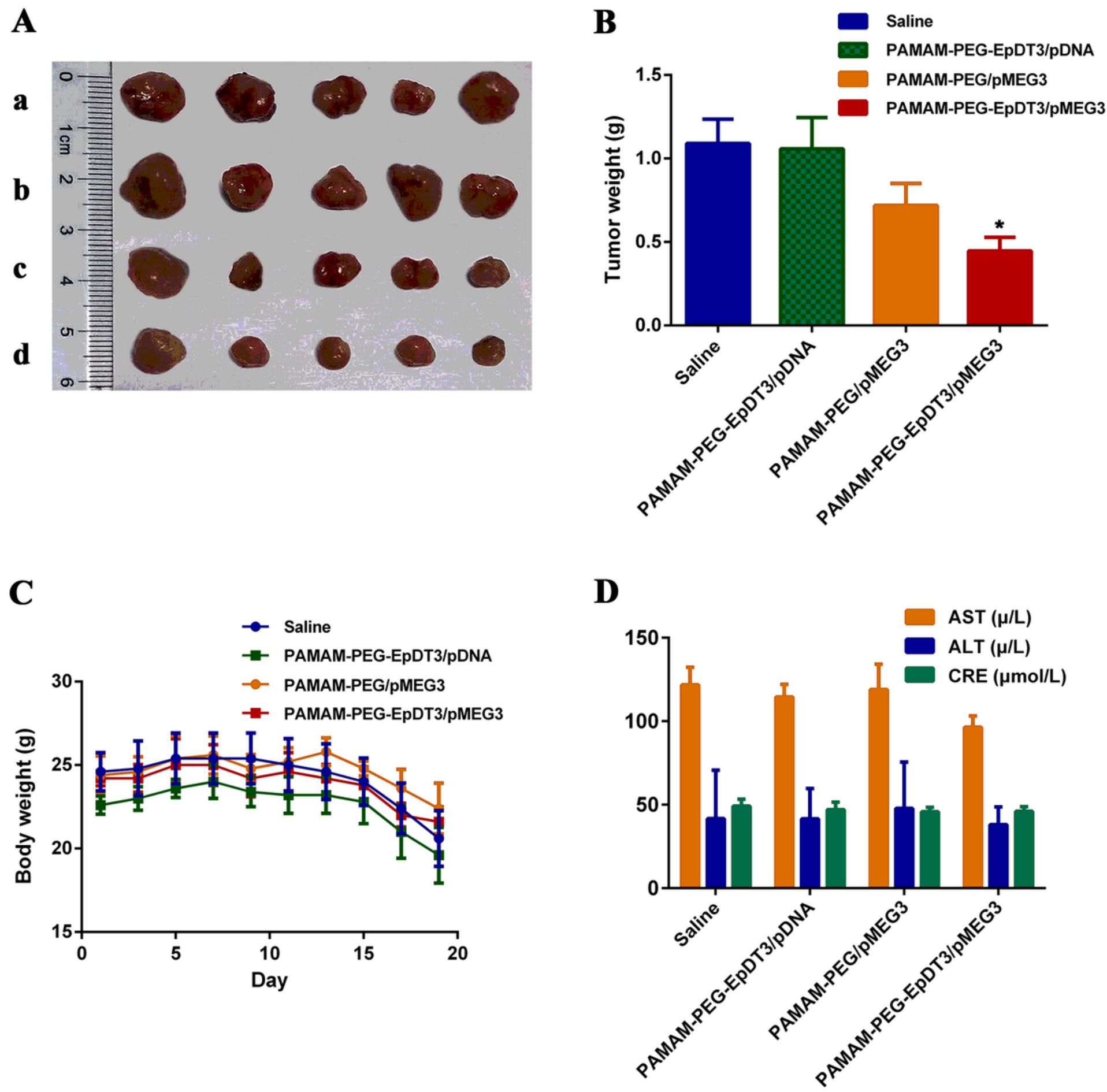

Figure 7

Antitumor effect and safety evaluation in tumor-bearing nude mice. (A) Tumor appearance after death of the CRPC-bearing nude mice (a. Saline; b. PAMAM-PEG-EpDT3/pDNA; c. PAMAM-PEG /pMEG3; $d$. PAMAM-PEG-EpDT3/pMEG3). (B) The average weight of tumors in different treatment groups $(n=5)$. (C) Weight curve of CRPC-bearing nude mice in therapeutic experiments $(n=5)$. (D) The result of the alanine aminotransferase, aspartate tranminase and cretinine of CRPC-bearing nudu mice after different treatment. ${ }^{*}<0.05$ compared to other groups. 
$\mathbf{A}$

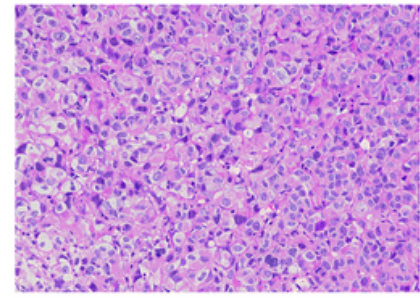

B

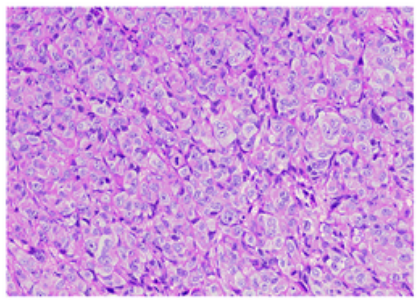

C

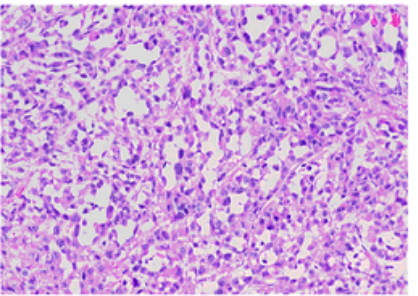

D

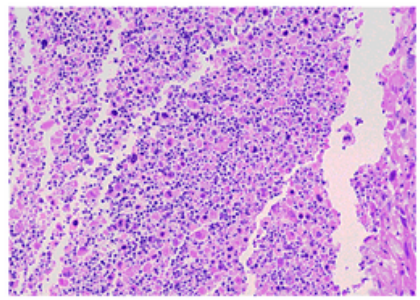

Ki67
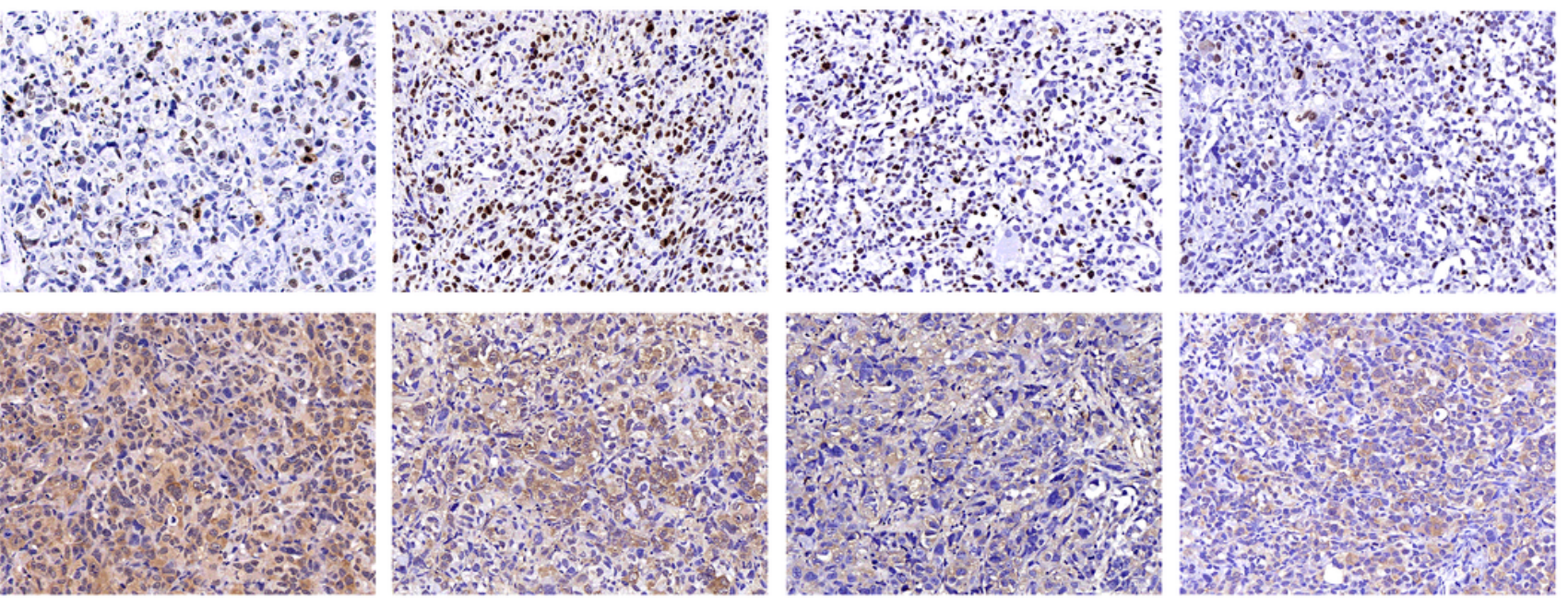

Bcl-2
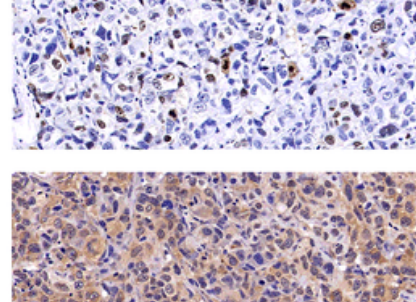

\section{Cyclin D1}
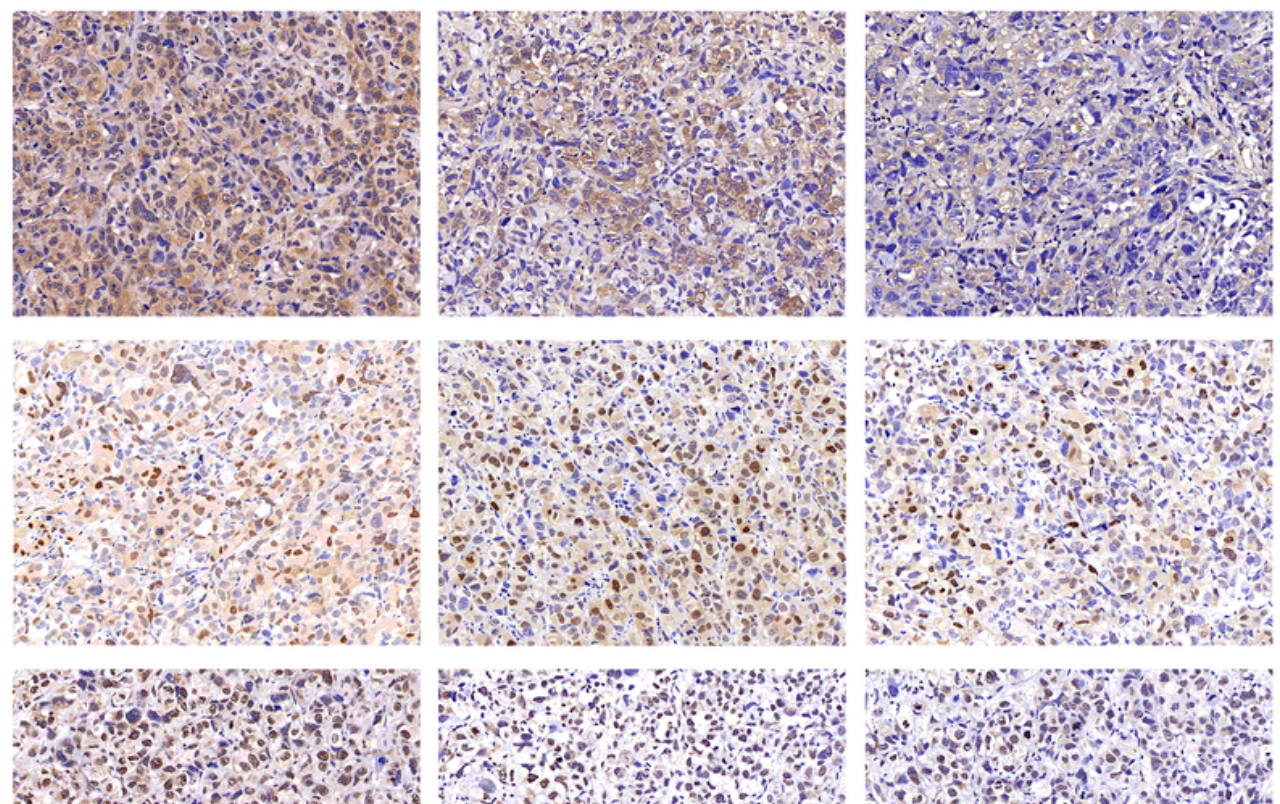

p53
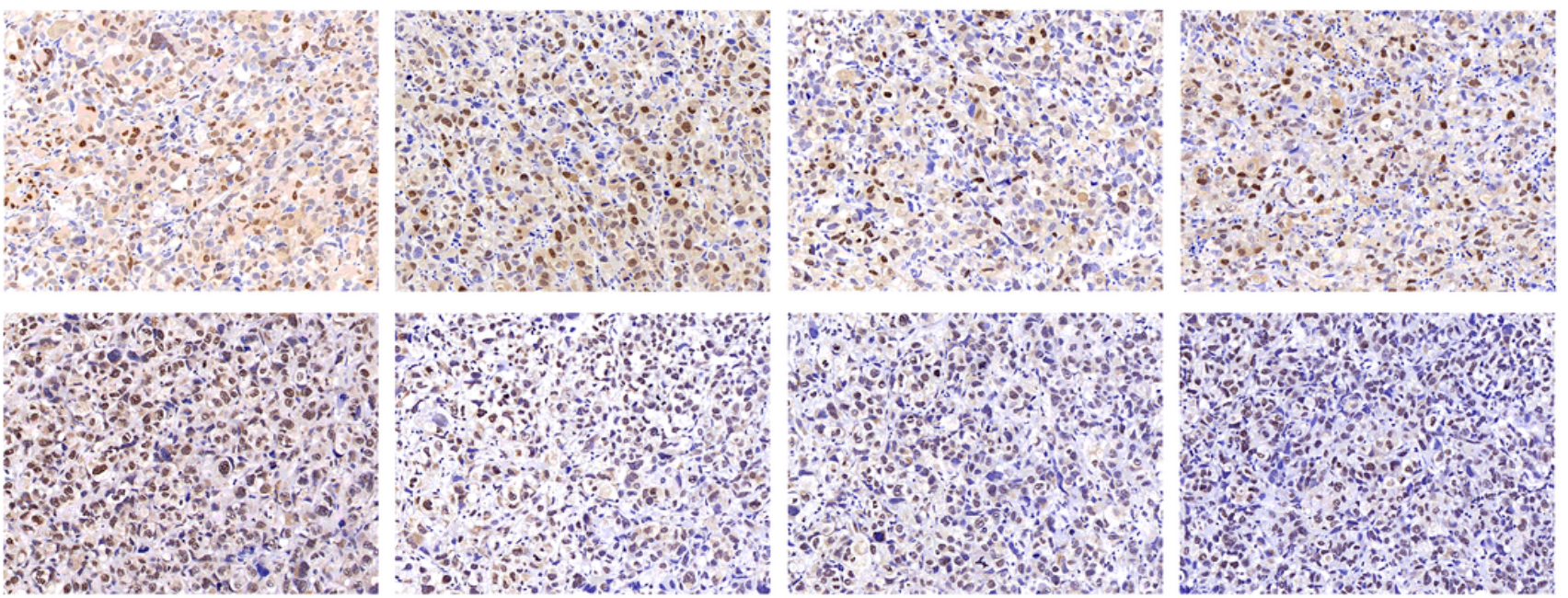

\section{Figure 8}

$\mathrm{H} \& \mathrm{E}$ staining to observe the tissue injury and immunohistochemistry to assess protein expression of the isolated tumors. (A. Saline; B. PAMAM-PEG-EpDT3/pDNA; C. PAMAM-PEG /pMEG3; D. PAMAM-PEG-

EpDT3/pMEG3). 